\title{
Sharpening the Axe: Identifying and Closing Gaps Within the Training Space of the South African Private Security Industry
}

\author{
Linda Mbana ${ }^{1, *}$, Jacob T. Mofokeng ${ }^{2}$, Witness Maluleke $^{2}$ and Dorcas Khosa ${ }^{1}$ \\ ${ }^{1}$ Department of Safety and Security Management, Faculty of Humanities, Tshwane University of Technology, \\ South Africa \\ ${ }^{2}$ Department of Criminology and Criminal Justice, University of Limpopo, South Africa
}

\begin{abstract}
The ever-present threat of crime in South Africa continues to drive the rise and demand for Private Security Industry (PSI) services amongst various governmental institutions, businesses and citizens to ensure their safety. This rise for the Private Security Services (PSS) persistently presents new challenges to the Private Security Industry Regulatory Authority (PSiRA) such as poor security training standards and deployment of untrained security officers attached to the Private Security Companies (PSCs), which negatively impacts the professionalism of the security industry. This study was guided by this objective: Identifying and closing the gaps within South African training space of PSI. This qualitative study was guided by the exploratory research design. The judgemental sampling technique was adopted to sample 40 participants confined to Gauteng (GP), Kwa-Zulu Natal (KZN) and Western Cape (WC) Provinces. The selected relevant stakeholders were attached to the South African Police Service (SAPS), Department of Labour (DoLI), Department of Home Affairs (DoH), National Prosecuting Authority (NPA) and the legal fraternity) and the PSI Directors and security officers to form part of the Focus Group Discussions (FGDs) and hybrid semi-structured interviews. The findings highlighted that the majority of the participants agreed that the private security industry training space is affected by security service providers letting PSiRA down by not training at, but rather engaging in, criminal activity through selling and people buying PSiRA security certificates. Some of the challenges mentioned include; poor training standards, non-compliance to legislated training standards, unqualified security training facilitators and outdated security Grades, misuse of security equipment leading to serious injuries and death, corruption in the industry, some of it being perpetrated by PSiRA inspectors, the very people who are supposed to keep the industry in check. This study recommends that, in order to overcome the challenges in the security training space, PSiRA needs to do away with the outdated security Grades by developing a new policy framework which will enable the creation of a new security-training curriculum and revise the training methods to suit the ever-changing security industry.
\end{abstract}

Keywords: Closing gaps, private security industry and training space.

\section{INTRODUCTION AND PROBLEM FORMULATION}

Protection of life, property and enforcement of social rules through trained men has always been a priority and considered a profession for the earliest man on earth. These needs have remained imperative to this very day and have contributed to the development of contemporary high-tech private security and modern law enforcements throughout the world, (Sefalafala and Webster, 2013). The Private Security Industry (PSI) continues to be an essential component of modern society and a strong influencer of the structure and function of modern policing. Private security has evolved into a multi-faceted profession with multiple specialities, employing millions of people, contributing greatly to South Africa's Gross Domestic Product (GDP), as well as demonstrating high probability of sustained growth in the future (Govender, 2013; Sefalafala and Webster, 2013).

It is an inarguable fact that security guards are the sentinels in private security companies, they are the

*Address correspondence to this author at the Department of Safety and Security Management, Faculty of Humanities, Tshwane University of Technology, South Africa; E-mail: khosad@tut.ac.za enforcers of policies and laws on the client premises. They are the key elements of peacekeeping inside company and client premises as they prevent theft, and other crimes from happening. For them to execute these duties well, security guards need proper training. Professional training provides the security personnel with the right knowledge, skills, and instincts crucial to the company's safety and survival. In today's modern world, security guards need to be a cut above the rest through professional and quality training. The protection of lives and property is an awesome societal responsibility, and the public interest demands that persons entrusted with such responsibilities be competent, well-trained, and of good moral character (Nemeth, 2012).

The security personnel should undergo intense training programmes to ensure both the safety of the organisation and their own survival. According to Berg and Gabi (2011), low standards negatively impact on the professionalism of the PSI, as well as on accountability. Officers are the frontline of contact with the public and, if not properly trained, may misuse their mandate and violate the human rights of members of the public. However, due to poor training of security officers in South Africa, a lot of challenges have 
emerged that are linked to poor training such as noncompliance, unethical conduct, excessive use of force, assaults, injuries and murder of innocent civilians at the hands of security guards, corruption and criminality.

The reviewed studies also discovered the rise of bogus training centres in the PSI, where people attempt to register with the Authority using fraudulent documents. There were several arrests made by the Authority following the information provided regarding the bogus training centres and individuals responsible for manufacturing fake training certificates, matric certificates, as well as fake identity documents. According to Independent Online [IOL], 2020), a suspect was arrested by the Mtubatuba SAPS who were acting on information provided by an informant who was caught trying to register with a fake security and training certificate, at the PSiRA office in the KZN Province, Durban. These challenges caused huge dents in PSiRA's normative regulatory system that incapacitated it to adequately attend to the industry's major challenges and fully professionalise the industry (Berg and Howell, 2017).

Efforts to upgrade and professionalise the industry in South Africa have been done through enactment of various pieces of legislation and establishment of an independent regulatory body by the State, PSiRA (Sefalafala and Webster, 2013). However, even with such stringent efforts to professionalise the industry, challenges in the security training space continue to delay and impede the effectiveness of the enacted legislation. Some of the impeding factors were mentioned during an interview with Mr. Van Staden, the
Chief Operations Officer (COO) of PSiRA, who stated that "the industry is very much interested in having access to cheaper labour in order to render the services because they have got the inherent situation where clients see security as a grudge purchase; they don't really want to pay for it, but they require it because there are other pressures, maybe from their insurance houses. So, they are obliged to contract a private security to render a service that's needed, but it's still considered a grudge purchase and they want to get that service as cheap as possible." This contributes to the deployment of untrained security officers by private security companies so as to quickly meet the clients' security needs. Between April 2018 and March 2019 compliance inspections revealed that close to 238 businesses were deploying unregistered security officers, 206 businesses deploying untrained security officers, and 1792 unregistered security officers and 2 618 untrained security officers (PSiRA Annual Report, 2018/2019). The highest of these incidences were mainly reported in GP, WC and KZN after inspections of 6253 PSCs business premises by PSiRA inspectors.

The problem under research offer the challenges encountered in the training of security officers in the PSI leading to security companies deploying untrained security officers in GP, KZN and WC Provinces. Cobalt Security Services (2020), mentions that, in the event of a security breach security guards should be the first line of defence, however, if they are untrained, it is going to be difficult for them to neutralise the threat effectively without causing harm to themselves or others. According to the PSiRA 2018/2019 Report,

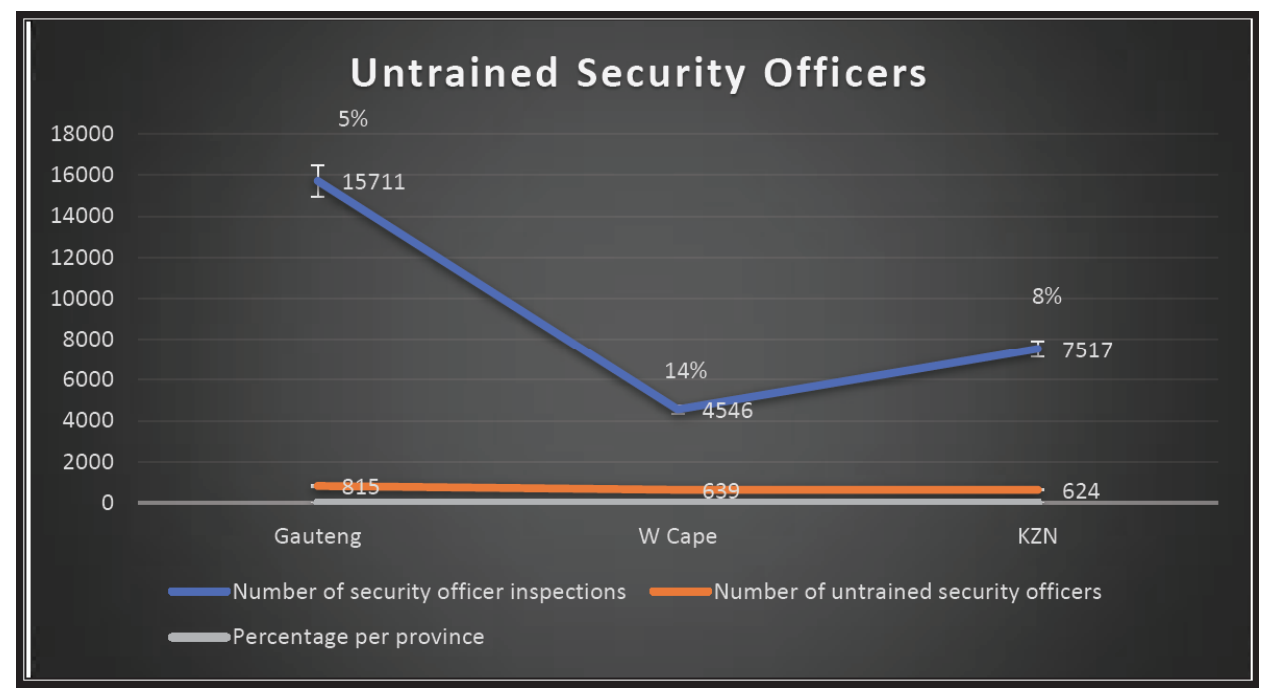

Figure 1: Untrained Security Officers 2018/2019 Financial Year.

Sources: PSiRA Annual Report (2018/2019). 
there are about 2078 untrained security guards working in GP, WC and KZN that have been discovered through inspections conducted during this financial period. The Figure $\mathbf{1}$ above, illustrates the number of untrained security officers discovered through inspections conducted during the 2018/2019 financial year.

It is evident from Figure $\mathbf{1}$ above, that untrained security officers do operate in the industry and their presence can have adverse outcomes. Due to lack of training, they can engage in bad practices, which could have serious consequences especially when such bad practices relate to the use of force and firearms which can result in serious injuries and sometimes death (Sefalafala and Webster, 2013). The PSiRA Act (No. 56 of 2001), Chapter 3 Sub-section 23 (c) outlines some of the requirements for registration for people wishing to become security officers; one of them being to comply with the relevant training requirements prescribed for registration as a security service provider. This criterion is clearly meant to deter the entry of all those who are considered to be unfit to work in the industry, but still the untrained security officers slip through this vetting process. Training of security guards has been a contentious issue in South Africa and the impact of low training have had a huge impact on the professionalisation of the industry (Nemeth, 2012).

\section{LITERATURE REVIEW}

\subsection{Challenges Affecting the Private Security Training Space}

Training for private security officers in the PSI is a concern for civil liberties and reputation of the profession. Critics argue that there is a lack of training and education standards in the PSI (Berg and Gabi, 2011; Loader and White, 2015). The effects of the poor training of private security guards go a long way as their lack of skills could result in poor handling of security equipment such as firearms, pepper spray, handcuffs, button sticks or security dogs. Untrained security guards who carry firearms assume an increased risk of injury to themselves and others which can result in serious injuries or death. The gaps in the PSI training space could be explained by the minimal recruitment requirements and the lack of proper training standards (Abudu et al., 2013). This gets even more complicated when security officers work in mass public spaces such as shopping malls or universities. Training improves tactical and operational competence; thus indirectly contributing to improved security and professional conduct by security officers.

The lack of proper ethics, training, and educational readiness results in a probable scarcity of skilled and compliant security practitioners. The promotion of these traits and professional characteristics could curb a plethora of common private security enforcement problems, including the unnecessary use of force, false imprisonment, false arrest assertions, civilian death, improper or illegal search and seizure techniques, proliferation of lawsuits, misuse of weaponry, and abuse of authority. Many PSI personnel are only temporary or part-time employees who are often underpaid and untrained for their work. The protection of lives and property is a huge societal responsibility, and the public interest demands that persons entrusted with such responsibilities to be competent, well trained, and have good moral character (Nemeth, 2012).

Professionalisation of the private security industry remains a hard-to-reach target without commitment to good training standards within the PSI (Nemeth, 2017). Ndungu (2020), expresses that training is one of the main private security area that needs regulatory strengthening and improvement. There are many security officers who are conscientious and proficient in their work at the same time others are inadequately trained and thus present a potential hazard to the public especially in crowd control situations and to their employer. Training of security officers is important for the development of appropriate social and ethical behaviour and for proper use of authority entrusted to them and security equipment such as firearms, handcuffs, security dogs, and button sticks and to prepare security officers for potential threats associated with dealing with security threats.

One other challenge affecting the PSI training space is the lack of distinct role between PSiRA and Safety \& Security Sector Education and Training Authority [SASSETA]. There is no collaboration between the two entities. The training that is offered by PSiRA is done in a week and it does not give out the desired competence compared to the SASSETA one. The National Qualifications Framework [NQF] uses the credit-bearing system which determines the duration and the quality of the course. When one looks into the security officer training Grade E, offered by PSiRA, there is a big gap. PSiRA offers a 5-day course and the same programme in another platform on the NQF system, offered by SASSETA runs for a minimum duration of 3 months which is not quick, convenient and 
cost-effective for security learners who opt for the PSiRA Grades so they can quickly get employment. This does not guarantee the quality of the training as training can be rushed and certain key aspects of security can be ignored in the PSiRA Grades.

The government has a broader policy in terms of developing occupations through the Sector Education and Training Authority [SETAs], although PSiRA is a regulator, it does not really participate significantly enough in ensuring that the right qualifications are being developed by the QCTOs in this particular environment. PSiRA is a self-funding organisation, so it derives its revenue from holding on to security training of security officers, it does not really partner with the SETA because it does not want the SETA to take over the quality assurance of training because it will lose revenue emanating from submitted course reports (PSiRA, 2018). The other challenge in the PSI training space is in the area of the Firearm Act and PSiRA enforcement department, Berg and Gabi (2011) observed that firearms were not being effectively monitored resulting in firearms being issued and used by untrained, unqualified and unlicensed staff. There was a lack of a database for registering PSC firearms and lack of effective inspection of firearm serial numbers and the dependence of PSiRA on SAPS in dealing with misconduct. SAPS is legally able to conduct firearm inspections according to the Firearms Act, 2000. The PSCs have negative perceptions and suspect the firearms controls as just another moneymaking scheme by the authorities.

Other challenges exposed in the PSI training space according to Provost (2017), emerge from the unequal buying power between the rich and the poor which exacerbates disparities between the wealthy clients who are protected by increasingly sophisticated systems and the poor, who may need to resort to informal and sometimes illegal means to secure their safety. This fuels the use of untrained security officers and unlicensed firearms to provide very cheap and sub-standard private security services to those willing to pay less for security services, which adversely tarnishes the image of the private security industry. Berg and Gabi (2011), Loader and White (2015), agree that there is lack of adequate oversight in the regulation of training in the security industry.

According to the North Atlantic Treaty Organisation [NATO] - Democratic Control of Armed Forces [DCAF] (2010), the lack of oversight mechanisms and absence of adequate rules and regulations can create an atmosphere prone to corrupt tendencies by untrained private security officers leading to loss of revenue and other resources. When untrained security officers easily gain access to firearms during their duty, registered or illegal, it makes it easy for them to take the law into their hands and act maliciously which could lead to serious accidents or deaths (Tracey, 2011). While private security industry is a vast crime prevention and reduction resource, it will for the most part remain only a potential resource until steps are taken to improve the quality of private security training.

\subsection{Effectiveness of PSiRA's Strategies in Ensuring Quality Training of Security Officers within the Industry}

The PSiRA establishes the minimum mandatory standards of training for private security personnel, which is an important part of any regulation (PSiRA, 2018). Training is conducted by private security training service providers who are PSiRA accredited to provide security training using PSiRA approved training content. Standardisation of private security training levels the playing field for PSCs and mitigates against the downward competitive forces which often create a 'race to the bottom' in which training quality suffers. One of the objectives of the Private Security Regulator is to promote high standards in the training of security service providers and prospective security providers.

The security training centres play a major role in the development of the security industry itself and PSiRA mandates them in terms of their accreditation to fulfil the development. The skills development part of it which is inherently challenging as not all training centres are accredited by PSiRA. Training service providers are required by law to be registered and accredited with PSiRA before they can offer any training services. Therefore, PSiRA determines the minimum statutory training standards for the industry, accredits training centres and instructors to present PSiRA statutory courses which include Security Grades E - A, Assets in Transit, Reaction Services, Event Security and Dog Handlers, evaluates and processes course reports, liaises with South African Qualifications Authority (SAQA), QCTO and SASSETA in respect of the development of NQF qualification and programs for all categories or classes of security service providers, and recognition of prior learning (PSiRA, 2018).

The security training service providers can be accredited and inspected for evaluation, if they complete the Accreditation Application form (PSiRA 
Form $47 \mathrm{~A}$ ), have proof of registration with PSiRA in the form of a registration certificate copy, proof of payment of the prescribed accreditation fee, receipt of the settlement of annual fees, lease agreement (of the approved infrastructure assessment for the purpose of training), with a 6 month validity period and a signed confirmation letter (on an official letter head of the training centre), proof of a fire department letter or affidavit, signed confirmation letter (on the official letterhead) of instructor(s), instructor certificate and employment contract, policy and procedures prescribed for the management and administration of training, proof of a telephone line and proof of a fax line (PSiRA, 2018).

One of the requisite elements that give effect to PSiRA's mandate in ensuring a well-regulated PSI training space is the development and implementation of a compliance and enforcement strategy. Part of the enforcement is to deter bad behaviour. Issues of ethics, moral degradation and threats posed to the general public by the private security industry can no longer be ignored (Berg, 2017). Compliance is a state of accordance between a professional member's behaviour or products on the one side, and predefined explicit rules, procedures, conventions, standards, guidelines, principles, legislation or other norms on the other side (Foorthuis and Bos, 2011). PSiRA ensures compliance to legislation through active monitoring and investigating the affairs of security training service providers and security officers with its inspectors from the Law Enforcement department. The PSiRA determines and enforces minimum standards of occupational conduct and training in respect of security service providers. In this regard, the Authority has a dual responsibility of determining minimum standards of training and occupational conduct in respect of security service providers as well as enforcing such standards (PSiRA, 2018).

The PSI makes use of firearms as one of their primary means of deterring crime, self-protection and safeguarding their clients. Therefore, firearms need to be registered and regulated, which is done through the Firearms Control Act (No. 60 of 2000) and the Regulations of 2004. The Firearms control legislation requires all security personnel to be trained at an accredited training facility and acquire a competency certificate before being issued with a firearm by a PSC (the Firearms Control Act, No. 60 of 2000).

Compliance inspections can be regulatory, training, infrastructure, or accreditation inspections. PSiRA is also involved in a number of operations with other state agencies like SAPS, Department of Labour [DEL], DoH and the Firearms Control Registry. The focus of these operations is compliance with the PSiRA Act, 2001 and checks for deployment of unregistered and untrained security officers, illegal immigrants as well as compliance with the Firearms Control Act, 2000. About 53 such operations were conducted in the 2018-2019 financial year. Other inspections done by PSiRA to ensure compliance in the private security industry include 2298 improper conduct investigations, 673 improper conduct investigation dockets pertaining to exploitation of labour, 1056 criminal investigations, 1 498 firearm inspections, 1885 charge sheets and summonses, complaints and help desk and prosecutions (PSiRA, 2019). The competency certificate is renewed every five years and to qualify one needs to be a South African citizen, demonstrate knowledge of the firearms legislation, be mentally stable and not inclined to violence, not have been convicted within or outside South Africa of any offences outlined by the Act and they have completed a prescribed test in the knowledge of the Act, as well as having completed training and tests with regard to handling a firearm and tests for using a firearm in the course of security duties, the Firearms Control Act (No. 60 of 2000). The Act places the onus on PSCs to keep a register of all their firearms and to make provision for the storage and/or transportation.

\subsection{Recommended Approaches to Address Challenges in the Security Training Space which can Help with Professionalising the Industry}

Training typically has specific goals of improving one's competence, capacity, performance, and knowledge (United Nations Office on Drugs and Crime [UNODC], 2014). Regulatory bodies throughout the United States (US) have been placing heightened emphasis on education and training as part of the minimum qualifications of an applicant. One of the most important issues in raising the standards of the private security industry is training of security personnel. There are mandatory training standards that must be met for security personnel to be registered with any PSiRA (Mccrie, 2017). PSiRA requires security personnel to undergo at least 40 hours of training per security Grade, while Hungary basic security officer training is mandated at 320 hours (UNODC, 2014). Mandatory training standards can help to prevent the risk of security officers acting in a way that is inappropriate to public safety and prevention of crime as well as 
enhancing efforts to increase professionalisation and delivery of quality services (UNODC, 2014).

Berg (2017), believes that training must be monitored for compliance purposes, not for commercialising it for revenue stream by the selffunding training colleges which results in the security industry attracting and being flooded by school-leavers desperate for employment opportunities which damages the image and the reputation of the PSI. PSiRA (2019), strongly maintains that diversification of industry training needs to be enabled by the lifting of the moratorium in respect of new applications for security training providers, which allows security training providers to open new branches in different provinces. PSiRA does not tolerate unscrupulous security training providers, therefore, an effort is created for fair participation of the industry environment. In August 2018, the number of accredited security training providers stood at 480 . Thirteen capacity-building workshops were conducted in all the provinces.

PSiRA should into a Memorandum of Understanding (MoU) with the Technical and Vocational Education and Training (TVET) Council, security training providers, DoE, SASSETA, QCTO, SAQA and NQF to gain traction in the TVET landscape. The MoUs will enable PSiRA to establish and recognise these structures as assessment centres for credible assessment in certifying and accrediting prospective and constituent security officers (PSiRA, 2019).

According to PSiRA (2019), it is recommended that by the year 2030, PSiRA should properly vet and screen security training provider applicants, increasing training and skills development, and accrediting new training centres to provide an equal opportunity for all businesses interested in providing security training to apply for accreditation. PSiRA should increase the national footprint of training centres in the country in order to improve accessibility to prospective persons interested in a career in the PSI (PSiRA, 2019). PSiRA needs to take considerable steps to review the training curriculum of all security courses in order to improve the competency and skills required to render private security training services in increasingly challenging external environments.

\section{METHODS AND MATERIALS}

The objective of this qualitative study was to identify and close the existing gaps within South African training space of PSI. This was accomplished through the application of exploratory research design. The judgemental sampling method was employed to select 40 participants, extracted from the following stakeholders; the SAPS, DoL, DoH, NPA, legal fraternity personnel', the PSI Directors and security officers from GP, KZN and WC Provinces. The targeted sample was subjected to the FGDs and hybrid semistructured interviews. The collected data was analysed through the use of Thematic Content. The ethical clearance was obtained from the targeted PSIs, while adhering to PSiRA research ethical principles in the service. Moreover, the Tshwane University of Technology (TUT) policy on research ethics also ethically guided this study.

\section{RESULTS AND DISCUSSION}

Consciousness of the training challenges and addressing them in the private security industry is important for PSiRA if it is to successfully professionalise the PSI. For the purposes of this study, various statements were formulated by participants with the intention to describe the predominant training challenges affecting the industry, the deployment of untrained security officers and their impact on the overall image of the security industry at large.

\subsection{Demographic Characteristics of the Selected Participants}

Biographical information includes the data about the individual's experiences, age, gender, or skills which are strong indicators that set individuals apart. As initially explained, there were 40 participants in this study. The biographical data of these participants are presented according to the targeted provinces, participant number, work experience, age, and gender, as depicted in Table 1.

The results from Table 1 shows that 5 participants for the FGDs were from GP Province; their work experience ranging from 13 to 35 years; their ages ranged from 40 to 60 and were predominantly male with $1 / 5$ female participants. Moreover, the results show that 5 participants were from KZN Province; their work experience also ranged from 15 to 35 years; their ages ranged from 40 to 60 and were largely male with $1 / 5$ female participants. The results further reveal that 5 participants were from WC Province; their work experience ranging from 14 to 22; their ages ranged from 40 to 60 years and $2 / 5$ of the participants were female. 
Table 1: Biographical Data of the Selected 20 Focus Group Discussion Study Participants

\begin{tabular}{|c|c|}
\hline \multicolumn{2}{|l|}{ Keys: } \\
\hline Code Name & Full Participant Code Name \\
\hline \hline FGD 1-5 & Gauteng Focus Group Participant \\
\hline FW 1-5 & Western Cape Focus Group Participant \\
\hline FK 1-5 & Kwa-Zulu Natal Focus Group Participant \\
\hline FN 1-5 & National Focus Group Participant \\
\hline
\end{tabular}

\begin{tabular}{|c|c|c|c|c|}
\hline Province & Participants & Experience & Age & Gender \\
\hline \hline \multirow{2}{*}{ GP } & FGD1 & 35 & $50-60$ & Male \\
& FGD2 & 15 & $40-50$ & Male \\
& FGD3 & 17 & $40-50$ & Female \\
& FGD4 & 15 & $40-50$ & Male \\
& FGD5 & 13 & $50-60$ & Male \\
\hline WC & FW1 & 20 & $50-60$ & Male \\
& FW2 & 14 & $40-50$ & Male \\
& FW3 & 15 & $40-50$ & Female \\
& FW4 & 22 & $40-50$ & Male \\
& FW5 & 15 & $40-50$ & Female \\
\hline \multirow{2}{*}{ KZN } & FK1 & 22 & $40-50$ & Male \\
& FK2 & 30 & $50-60$ & Male \\
& FK3 & 35 & $50-60$ & Male \\
& FK4 & 15 & $40-50$ & Female \\
& FK5 & 16 & $40-50$ & Male \\
\hline \multirow{6}{*}{ National } & FN1 & 7 & $30-40$ & Female \\
& FN2 & 20 & $30-40$ & Male \\
& FN3 & 25 & $40-50$ & Male \\
& FN4 & 15 & $40-50$ & Male \\
& FN5 & 20 & $40-50$ & Male \\
\hline
\end{tabular}

Source: Researcher's illustration.

The results from Table 2 show that 8 participants were from GP Province; their work experience ranged from 4 to 27 years; their ages ranged from 30 to 60 and were predominantly male. Moreover, the results show that 6 participants were from KZN Province; their work experience also ranged from 5 to 19 years; their ages ranged from 30 to 80 and were largely male. The results further reveal that 6 participants were from WC Province; their work experience ranged from 10 to 27 ; their ages ranged from 40 to 60 years and $1 / 3$ of the participants were female.

The following section presents the qualitative findings from FGDs and hybrid semi-structured interviews conducted with participants. It presents the analysis of their verbal responses during the interviews and FGDs and presented as themes. Themes arise from engagement of a particular researcher with the
Table 2: Biographical Data of the Selected 20 Hybrid Semi-Structured Interview Study Participants

\begin{tabular}{|c|c|}
\hline \multicolumn{2}{|l|}{ Keys: } \\
\hline Code Name & Full Participant Code Name \\
\hline \hline G 1-8 & Gauteng Face to face interview Participant \\
\hline K 1-6 & Kwa-Zulu Natal face to face interview participant \\
\hline W 1-6 & Western Cape face to face interview Participant \\
\hline
\end{tabular}

\begin{tabular}{|c|c|c|c|c|}
\hline Province & Participants & Experience & Age & Gender \\
\hline \hline \multirow{2}{*}{ GP } & G1 & 25 & $40-50$ & Male \\
& G2 & 15 & $40-50$ & Male \\
& G3 & 6 & $50-60$ & Male \\
& G4 & 13 & $40-50$ & Male \\
& G5 & 11 & $40-50$ & Male \\
& G6 & 10 & $30-40$ & Male \\
& G7 & 15 & $40-50$ & Male \\
& G8 & 4 & $50-60$ & Male \\
\hline \multirow{2}{*}{ KZN } & K1 & 19 & $50-60$ & Male \\
& K2 & 17 & $50-60$ & Male \\
& K3 & 11 & $50-60$ & Male \\
& K4 & 9 & $70-80$ & Male \\
& K5 & 5 & $40-50$ & Male \\
& K6 & 6 & $30-40$ & Male \\
\hline \multirow{2}{*}{ WC } & W1 & 27 & $50-60$ & Male \\
& W2 & 23 & $50-60$ & Male \\
& W3 & 25 & $50-60$ & Female \\
& W4 & 10 & $40-50$ & Male \\
& W5 & 25 & $50-60$ & Female \\
& W6 & 22 & $50-60$ & Male \\
\hline
\end{tabular}

Source: Researcher's illustration.

text, as the researcher to address a particular research question. Themes are, therefore, pragmatic tools to help the researcher produce an account of the data. A code in qualitative inquiry is often a word or short phrase symbolically assigning a summative, salient, essence-capturing and evocative attribute for a portion of language-based or visual data (Saldana, 2015). The content and thematic analysis performed on the FGDs and hybrid semi-structured interview transcripts yielded four themes discussed below. It is worth mentioning that there are overlaps between some of the following emerged study themes:

- Theme 1: Challenges affecting the private security training space.

- $\quad$ Theme 2: Effectiveness of PSiRA's strategies in ensuring quality training of security officers within the industry. 
- Theme 3: Recommended approaches to address challenges in the security training space which can help with professionalising the industry.

\section{Theme 1: Factors Affecting the Private Security Training Space}

The PSI still continues to undergo various regulatory changes in a bid to professionalise it; however, it continues to face challenges and many factors working against PSiRA's professionalisation efforts. To answer the research questions: What are the main challenges affecting the private security industry training space? The participants provided information about their observations and experiences concerning challenges within the security training space within GP, KZN and WC Provinces. From the findings of this study the following sub-theme emerged in an endeavour to illuminate on the challenges in the security training space. The sub-themes are; Training, Corruption and Criminality.

Theme 2: Effectiveness of PSiRA's Strategies in Ensuring Quality Training of Security Officers within the Private Security Industry

In terms of section 4 of the PSiRA, 2001, this Authority must take steps as may be necessary to develop and maintain standards (including training standards), and regulate practices of security service providers. The Authority must take steps that may be expedient or necessary in connection with the training of security service providers to ensure a high quality of training, and in particular the determination and accreditation of qualifications required by security service providers to perform particular types of security services and taking reasonable steps to verify the authenticity of training presented by persons for the purposes of this Act. To answer this research question: How effective are PSiRA's strategies in ensuring quality training of security officers within the industry? The participants were requested to provide their experiences and observations about the strategies of PSiRA. From the analysis, the following four subthemes emerged as strategies being used by PSiRA to ensure quality training from this question: Transformative strategies, Strategic collaboration with stakeholders and Law enforcement.

Theme 3: Recommended Approaches to Address Challenges in the Security Training Space which can Help to Professionalise the Private Security Industry

This question was also posed to the selected participants: What recommended approaches can address the challenges in the private security training space which can help to professionalise the industry? The participants were requested to provide possible corrective approaches and measures that PSiRA could implement to advance the professionalisation of the private security industry. Six codes emerged from the analysis of the participants' responses. These codes were: updating the training curriculum and method of training, empowering and training more inspectors, building relationships and working closely with education sector stakeholders.

\section{CONCLUSIONS AND RECOMMENDATIONS}

The following conclusions can be drawn from the results of the study. Training security officers leads to security officers becoming more attentive to details and be more alert while on the job. With increased alertness, security officers will be better able to recognise and report any incidents which will also increase the efficiency of the communication. Security guard training will teach the importance of communication that is clear, concise, and easy to understand and its role in effective security operations. Properly training security officers improves the intelligence of the security officers, allowing them to more easily handle circumstances in a responsible and appropriate manner while under duress. Having the training to make difficult decisions during stressful circumstances will not only increase the efficiency of the security guard's performance, but it will also optimize the safety of the security guard. Despite the persistent challenges in the private security training space, if all stakeholders (Security training providers, Department of Education (DoE), SASSETA, QCTO, SAQA and NQF), worked together with PSiRA to address them, they would effectively professionalise the private security industry.

To overcome the challenges in the private security training space, the following recommendations are made:

- Update the new training curriculum through a policy framework to ensure that training material is relevant and up to date and ensuring quality training. The PSI keeps growing and evolving. With that growth and evolution, the curriculum should be reactive and incorporate these new changes, so that security training can produce security officers that are competitive and proactive in crime fighting. Some of the proposed changes with regard to training include setting 
minimum training instructor standards, changing the method of training from instructor-based approach to a more flexible and interactive student-centric approach.

- $\quad$ Empower and train more inspectors. Importantly: trained PSiRA inspectors could attend to a lot of challenges in the training space by regular inspections of security training service providers, not only to enforce the legislation, but be capacitated to teach and train security service providers on security training issues and concerns.

- $\quad$ Build relationships and collaborative partnerships with education sector stakeholders. PSiRA is advised to forge working relationships and collaborative partnerships with key stakeholders in the education and skills development sector such as Department of Education, SASSETA, QCTO, NQF and SAQA to get a helping hand in addressing the challenges in the security training space. These stakeholders could assist PSiRA with the development of new qualifications thus further expanding the private security industry ensuring the sustainability of the PSI.

\section{REFERENCES}

Abudu, A. M., Nuhu, Y. and Nkuah, K. J. 2013. Bridging the Security gap in Ghana: The role of Private Security Actors. Developing Country Studies Vol. 3(10), 11-31.

ATLAS.ti. 2020. Atlas.ti Qualitative Data Analysis. Available from: https://atlasti.com/product/what-is-atlas-ti/. [Accessed: 6/09/2020].

Berg, J. 2017. Private security in Africa: Time to regulate the bad and harness the good. Available from: https://theconversation.com/private-securityin-africa-time-to-regulate-the-bad-and-harness-the-good-85793. [Accessed: 10/04/2020].

Berg, J. and Gabi, V. 2011. Regulating Private Security in South Africa; Context, challenges and recommendations. African Policing Civilian Oversight Forum.

Berg, J. and Howell, S. 2017. The Private security complex and its regulation in Africa: select examples from the continent. International Journal of Comparative and Applied Criminal Justice, 1-14 https://doi.org/10.1080/01924036.2017.1364280

Creswell, J. W. and Creswell, J. D. 2018. Research Design, Qualitative, Quantitative \& Mixed Methods Approaches. 5th Edition. Los Angeles: SAGE

Cobalt Security Services 2020. Untrained guards problem for security companies. Available from: https://cobaltsecurityservices.com/ untrained-guards-problem-for-security-companies/ [Accessed: 23/08/2020].
Florquin, N. and Morales, A. 2011. A Booming Business Private Security and Small Arms. Available from: https://www.academia.edu/24018866/. [Accessed: 12/04/2020].

Foorthuis, R. and Bos, R. 2011. A Framework for Organizational Compliance Management Tactics. London: GRCIS, CAiSE Workshop on Governance, Risk and Compliance. https://doi.org/10.1007/978-3-642-22056-2 28

Govender, D. 2020. Private Security Involvement in Crime Prevention: A Critical Evaluation. Available from: https://www.saps.gov.za/ resource_centre/publications/prof_govender_saps_research_colliquiu $m$ critical evaluation.pdf. [Accessed: 12/12/2020].

Independent Online 2020. Second suspect arrested in fake certificates bust. Available from: https://www.iol.co.za/mercury/news/second-suspectarrested-in-fake-certificates-bust-18449103 https://ewn.co.za/2013/05/06/Fake-security-certificates-been-aroundfor-year. [Accessed on: 27/09/2020]

Loader, I. and White, A. 2015. How can we better align private security with the public interest? Towards a civilizing model of regulation. Wiley Publishing Asia Pty Ltd https://doi.org/10.1111/rego.12109

Mccrie, R. 2017. Private security services regulations in the United States today. Journal of Comparative and Applied Criminal Justice Vol. 41 $1-18$. https://doi.org/10.1080/01924036.2017.1364281

Ndungu, B. 2020. The need to regulate private security in Zambia. International Journal of Scientific \& Engineering Research Vol. 11 (4), 1-109.

Nemeth, C. P. 2012. The law of Arrest, Search, and Seizure (Fourth Edition.) Butterworth: Elsevier Inc. https://doi.org/10.1016/B978-0-12-386922-7.00006-X

Nemeth, P. C. 2017. Private Security and the Law (5th Edition). Boca Raton: CRC Press. https://doi.org/10.4324/9781315157191-5

North Atlantic Treaty Organisation [NATO] - Democratic Control of Armed Forces [DCAF]. 2010. Building Integrity and Reducing Corruption in Defence. A compendium of Best Practices. Available from: https://securitysectorintegrity.com/publication/building-integrityreducing-corruption-defence-compendium-best-practices/. [Accessed: 3/09/2020].

Private Security Industry Regulatory Authority [PSIRA]. 2017. Annual Report 2016-2017. Centurion: PSIRA.

Private Security Regulatory Authority (PSIRA). 2018. Executive Committee. Available from: https://www.psira.co.za/search-joomla/executivemanagement.html. [Accessed: 10/08/2020].

Private Security Regulatory Authority [PSIRA]. 2019. Annual Report 2018-2019. Centurion: PSIRA

Provost, C. 2017. The Guardian: The Industry of Inequality: why the world is obsessed with private security. Available from: https://www.theguardian.com/inequality/2017/may/12/industry-ofinequality-why-world-is-obsessed-with-private-security. [Accessed: 12/04/2020].

Rossman, G. B. and Rallis, S. F. 2012. Learning in the field: An introduction to qualitative researcch (3rd ed.). Thousand Oaks, CA: Sage.

Saldana, J. 2015. The Coding Manual for Qualitative Researchers Third Edition. New Jersey: Sage Publications.

Sefalafala, T. and Webster, E. 2013. Working as a Security Guard: the limits of Professionalisation in low Status Occupation. South African Review of Sociology, Vol. 44(2), 76-97. https://doi.org/10.1080/21528586.2013.802539

Tracey, L. 2011. Implementing the South African Firearms Control: A complete failure or work in progress? Pretoria: Institute for Security Studies.

United Nations Office on Drugs and Crime. 2014. Global Report on Trafficking Persons. Available from: https://www.unodc.org/unodc/en/data-andanalysis/glotip 2014.html [Accessed: 15/04/2020].

Received on 02-08-2021

Accepted on 16-09-2021

Published on 21-10-2021

https://doi.org/10.6000/1929-4409.2021.10.161

(C) 2021 Mbana et al.; Licensee Lifescience Global.

This is an open access article licensed under the terms of the Creative Commons Attribution License (http://creativecommons.org/licenses/by/4.0/) which permits unrestricted use, distribution and reproduction in any medium, provided the work is properly cited. 